\title{
Os Impactos da Lei de Responsabilidade Fiscal sobre as Receitas do Itbi no Paraná, no Período de 1997 a 2011: uma Análise a partir da Mesorregião Metropolitana de Curitiba
}

Rogélio Gerônimo dos Santos ${ }^{1}$

Sidnei Pereira do Nascimento ${ }^{2}$

Resumo: O objetivo deste estudo é aferir o comportamento das receitas per capita do Imposto sobre Transferências de Bens Imóveis (ITBI) entre a mesorregião Metropolitana de Curitiba e as demais mesorregiões do Estado do Paraná, no período de 1997 a 2011, sob os impactos da Lei de Responsabilidade Fiscal (LRF). Para isso, utiliza-se o modelo econométrico de Ajustes de Poligonais e do Índice de Gini. Os resultados econométricos demostram que as demais mesorregiões do Estado, na média, obtiveram taxas variações negativas na participação per capita do ITBI em relação à mesorregião Metropolitana de Curitiba no período de 2005-2011. O Índice de Gini permite visualizar pequena variação no que tange à desconcentração dessas receitas. Todavia, observam-se mudanças significativas na tendência a partir de 2005. Assim, constata-se que as demais mesorregiões não aumentaram suas receitas per capita do ITBI com a mesma intensidade da mesorregião Metropolitana de Curitiba, no período de 2005-2011.

Palavras-Chave: Receitas per capita do ITBI; Lei de Responsabilidade Fiscal; Mesorregião Metropolitana de Curitiba.

1 Graduado em Ciências Econômicas e Mestre em Economia Regional pela Universidade Estadual de Londrina (UEL). Professor pesquisador do curso de especialização em Gestão Pública da Universidade Estadual de Londrina (UEL). Professor do curso MBA em Auditoria e Perícia Contábil da UNIVEL \INBRAPE. E-mail: rogelio1974@sercomtel.com.br.

2 Graduado em Ciências Econômica pela UEL. Mestre em Economia pela UNB e Doutor em Economia Aplicada pela ESALQ/USP e Professor do Departamento de Economia da UEL. 
ABSTRACT: The objective of this study is to detect the behavior of per capita income Tax Transfers of Real Estate (TTRE) between the mesoregion of Curitiba and other mesoregions of the state, in the period from 1997 to 2011, under the impact of the Fiscal Responsibility Law (FRL). For this, we use the econometric model Adjustments Polygonal and Gini Index. The econometric results show that the remaining mesoregion state, on average, had negative growth rates in per capita participation ITBI compared to mesoregion Metropolitan of Curitiba in the period 2005-2011. The Gini Index allows you to view small change with respect to the devolution of these revenues. However, there are significant changes in the trend from 2005. Thus, it appears that the other mesoregion state has not increased its revenue per capita TTRE with the same intensity from the mesoregion Metropolitan of Curitiba, in the period from 2005 to 2011.

Keywords: Income per capita TTRE; Fiscal Responsibility Law; Mesoregion Metropolitan of Curitiba.

Jel: H2; H27

\section{Introdução}

Os recursos financeiros, frutos da arrecadação tributária, têm como finalidade garantir a oferta de serviços à população. Segundo Riani (1997), os gastos públicos são uma escolha política dos governos no que se refere aos serviços que são prestados à sociedade. Giambiagi e Além (2000) observam que os administradores públicos, quando fazem essas escolhas, deixam alguns grupos insatisfeitos. Dessa forma, os recursos oriundos dos impostos tem a finalidade, dentre outras, de preencher as lacunas das falhas de mercados. Os desafios dos gestores públicos são de minimizar os impactos negativos, buscando o máximo de eficiência entre os agentes financiadores e os que necessitam desses serviços ofertados pelo Estado.

O Imposto sobre Transmissão de Bens Imóveis (ITBI) é de competência dos municípios, delegado através do art. 156, inciso II da Constituição Federal de 1988. De forma geral, o fato gerador, é a transmissão de bens imóveis entre vivos (inter vivos), a qualquer título, por ato oneroso e a definição das alíquotas são fixadas através de lei emanadas dos municípios e não são estabelecidos tetos, mas é vedada a sua progressividade. 
A problemática relacionada a este estudo diz respeito à concentração das receitas per capita, oriundas do Imposto sobre Transmissão de Bens Imóveis (ITBI) na mesorregião Metropolitana de Curitiba, no período de 1997 a 2011, comparando-a com as outras mesorregiões do Estado do Paraná.

O objetivo dessa pesquisa é verificar o comportamento das receitas per capita, oriundas do Imposto sobre Transmissão de Bens Imóveis (ITBI), com análise entre a mesorregião Metropolitana de Curitiba e às demais mesorregiões do Estado, no período de 1997 a 2011. De forma mais específica busca-se avaliar os impactos da Lei de Responsabilidade Espacial (LRF) na arrecadação per capita do Imposto sobre Transmissão de Bens Imóveis (ITBI) nos municípios paranaenses, a partir de 2005, com todos os instrumentos de planejamento financeiro ${ }^{1}$ contemplados em conformidade com a Lei de Responsabilidade Fiscal (LRF).

A escolha da mesorregião Metropolitana de Curitiba foi motivada pela sua importância na arrecadação do Imposto sobre Transmissão de Bens Imóveis no Estado, que representou em 2011, 51,48\% de todas as receitas originadas do Imposto sobre Transmissão de Bens Imóveis no Estado do Paraná.

Dessa forma, alterações significativas em suas participações na arrecadação indicam informações de relevância para as demais mesorregiões do Estado. Em 2011 a mesorregião Metropolitana de Curitiba foi responsável por 57,69\% de toda a arrecadação própria de município, que são oriundas do Imposto Predial Territorial Urbano (IPTU), Imposto Sobre Serviços de Qualquer Natureza (ISSQN) e Imposto Sobre Transmissão de Bens Imóveis (ITBI) (Receita Federal 2012).

Para isso, foi utilizada a metodologia de análise econométrica, através dos Mínimos Quadrados Ordinários (MQO), com o modelo de Ajustes de Poligonais e o Índice de Gini, que permitirão avaliar o perfil comportamental das receitas per capita do Imposto sobre Transmissão de Bens Imóveis, no período compreendido entre os anos de 1997-2011 com quebra estrutural a partir de 2005 .

O artigo está estruturado em quatro partes, além desta introdução, da seguinte forma: contextualização econômica e jurídica; metodologia; descrição dos resultados; e considerações finais.

Destaca-se a importância deste estudo no segmento ligado à gestão tributária do setor público, que tem grande relevância e interesses socioeconômicos, visto que os investimentos com recursos financeiros oriundos desses impostos são de grande importância para o crescimento e desenvolvimento dos municípios. Ainda corrobora para implantação de políticas governamentais, que visam melhorar a arrecadação tributária municipal. 


\section{Contextualização econômica e jurídica}

Nesta seção faz-se uma breve caracterização da mesorregião Metropolitana de Curitiba, onde, destaca a sua representatividade na economia paranaense. Na subseção 2.2 apresenta a origem, a evolução histórica e a norma jurídica vigente que instituiu o Imposto Sobre Transmissão de Bens Imóveis (ITBI) no Brasil. E Por fim, expõem as justificativas da quebra estrutural para delimitar os dois períodos avaliados neste estudo.

\subsection{Perfil da Mesorregião Metropolitana de Curitiba}

A mesorregião Metropolitana de Curitiba é constituída por trinta e sete municípios, que correspondem a aproximadamente a 11\% do território estadual, com uma população em 2010, de 3,5 milhões de habitantes distribuídas em 1,3 milhões de domicílios (IBGE 2012). Dos trinta e sete municípios que compõem a mesorregião, nove tem população acima de 50 mil habitantes.

Essa mesorregião é agrupada em cinco microrregiões denominadas de Cerro Azul, Curitiba, Lapa, Paranaguá e Rio Negro. Geograficamente faz fronteira ao norte com o Estado de São Paulo, ao sul com Santa Catarina, a leste com o Oceano Atlântico, a noroeste com a mesorregião Centro Oriental, a sudoeste com a mesorregião Sudeste.

Em 2010 a mesorregião Metropolitana de Curitiba alcançou 1,9 milhões de pessoas na População Economicamente Ativa (PEA) e 1,8 milhões de pessoas na população ocupada, que corresponde a 94,90\% da População Economicamente Ativa (PEA) (IPARDES 2011).

O Valor Acrescentado Bruto (VAB) em 2010 alcançou de R \$ 83,9 bilhões com ênfase no setor de serviços que correspondeu a $68,95 \%$, seguido pelos setores industrial e agropecuário que correspondem, respectivamente, a $29,42 \%$ e 1,63\% (IPARDES 2011).

Quanto ao Valor Adicionado Fiscal (VAF) os valores alcançaram R 84,1 bilhões divididos da seguinte forma: $57,97 \%$ para o setor industrial; $1,22 \%$ para produção primária e 40,81\% para o setor de comércio e serviços. As receitas municipais alcançaram, em 2011, R $\$ 8,1$ bilhões e as despesas em $\mathrm{R} \$ 7,7$ bilhões, obtendo superávit fiscal de 4,47\% (IPARDES, 2011). A mesorregião ainda apresenta outros importantes indicadores como o PIB per capita de 2010 de R 20 mil, Índice de Idosos de 31,03\% da população 
(IBGE/IPARDES, 2012) e coeficientes de mortalidade infantil de 10,03 por mil nascimentos (SESA 2013).

\subsection{Impostos Sobre Transmissão de Bens Imóveis}

O objeto deste estudo, o Imposto Sobre Transmissão de Bens Imóveis (ITBI), de competência municipal, é um dos três impostos que formam a tríade junto com o Imposto sobre a Propriedade Territorial e Urbana (IPTU) e o Imposto Sobre Serviços de Qualquer Natureza (ISSQN). O ITBI é um imposto de transmissão inter vivos, a qualquer título, por ato oneroso, de bens imóveis, por natureza ou acessão física e de direitos reais sobre imóveis, exceto os de garantia, bem como cessão de direitos à sua aquisição (Brasil, 1988 ).

Oliveira (2009) lembra que a Emenda Constitucional $n^{0}$ 5/1961, dividiu a competência do causa mortis e do inter vivos, que era de competência exclusiva dos estados a sua cobrança, que então passou a ser de competência dos municípios, os poderes de instituir, fixar alíquotas e estabelecer normas de cobrança de transmissão de imóveis sobre as transações inter vivos. A competência dos estados ficou com o imposto incidente sobre a transmissão causa mortis. Conti (1999) vai além e observa que o imposto sobre transmissão de bens imóveis apareceu no Direito Brasileiro em 1809, denominado de SISA ${ }^{2}$, tendo a previsão constitucional a partir de 1891, outorgando aos estados a competência de sua arrecadação.

Conforme dispõe a Constituição vigente são três as hipóteses de incidência do Imposto Sobre Transmissão de Bens Imóveis (ITBI): a) a transmissão inter vivos, a qualquer título, por ato oneroso de bens imóveis, por natureza ou acessão física; (b) a transmissão de direitos reais sobre imóveis, excetos os de garantias; e (c) a cessão de direitos à sua aquisição (Barreto 2009).

Os sujeitos ativos do Imposto Sobre Transmissão de Bens Imóveis (ITBI), segundo Oliveira (2009), são os municípios e o Distrito Federal (art. 156, inciso II e art. 147 da CF/88). Barreto (2009) observa que o sujeito passivo é aquele de quem se deve exigir o pagamento do imposto.

Conforme descreve o Código Tributário Nacional (CTN) o fato gerador é o acontecimento expresso na norma jurídica legal como necessária e suficiente, normatizado por lei municipal (art.114 do CTN). Marinho (2012) lembra que o Imposto Sobre Transmissão de Bens Imóveis (ITBI) é ainda um dos poucos tributos no Brasil cujo lançamento é realizado por declaração do adquirente do imóvel à Fazenda Pública Municipal (Código Tributário Nacional 2011).

A base de cálculo é o valor venal dos bens e diretos transmitidos (art. 38, CTN).

2 SISA era o valor cobrado por transações imobiliárias que significava - Serviço de Imposto de Sua Alteza. 
Oliveira (2009: 242) entende que a base de cálculo é "o valor que se obteria no caso de a transação efetuar em condições normais". Barreto (2009) lembra que a base de cálculo é estabelecida por lei, que por sua vez define e fixa a sua base para se aplicar a alíquota correspondente.

Quanto às alíquotas, elas são fixadas através de lei municipal e não é estabelecido qualquer teto para tributação, segundo Barreto (2009). Oliveira (2009) afirma que é vedada a aplicação da progressividade no Imposto Sobre Transmissão de Bens Imóveis (ITBI) e que o Supremo Tribunal Federal (STF), mediante súmula já se manifestou contrário à progressividade do imposto que, em outra época, foi tributado dessa forma por alguns municípios. Todavia, observa-se que não há impedimentos de estabelecer, através de lei, diferentes alíquotas sobre os valores de imóveis adquiridos com recursos financeiros próprios ou por financiamento bancário.

\subsection{Justificativas da Quebra Estrututral}

A Lei Complementar 101/2000, conhecida por Lei de Responsabilidade Fiscal (LRF), tem como objetivo estabelecer normas de finanças públicas voltadas para responsabilidades na gestão fiscal.

A gestão fiscal implica na ação planejada e clara em que se antecipam os riscos e ajustam anormalidades capazes de afetar o equilíbrio das finanças públicas, mediante cumprimento de metas pré-estabelecidas nos instrumentos de planejamento financeiro entre receitas e despesas e à obediência aos limites e condições no que tange a renúncia de receitas.

Lino (2001) observa que com o advento da Lei de Responsabilidade Fiscal (LRF) o modelo de gestão da "máquina pública" pautada no welfare state ${ }^{3}$ deveria ser definitivamente encerrado. Dias (2009) argumenta que a forma intervencionista na gestão pública fundamentada na teoria econômica Keynesiana deveria ser substituída pela corrente neoliberal. Dessa forma, o governo

federal buscou executar, principalmente no período entre 1994-2002, uma política econômica pautada na austeridade fiscal, seguindo a "cartilha" de normas financeiras do Fundo Monetário Internacional (FMI).

Nesse contexto, em 2005, foram empossados os prefeitos para a primeira gestão com os três instrumentos de planejamento financeiro nas normas estabelecidas pela Lei de Responsabilidade Fiscal (LRF). Diferente do cenário de seus antecessores, empossados em 2001, que assumiram suas respectivas administrações com esses instrumentos já elaborados pelo Executivo e apro- 
vados pelo Legislativo, sem as exigências previstas na Lei de Responsabilidade Fiscal (LRF). Este foi o principal motivo para escolha do início do segundo período ser o ano de 2005 (SANTOS et al, 2014).

Conforme observa Andrade (2006) o processo de planejamento público inicia-se com o Plano Diretor ${ }^{4}$. Todavia, na área financeira ${ }^{5}$ os três instrumentos de planejamento são: O Plano Plurianual (PPA); Lei de Diretrizes Orçamentárias (LDO) e a Lei de Orçamento Anual (LOA). Esses instrumentos levam à eficiência na gestão da "máquina pública" e foram ratificados a sua importância com a Lei de Responsabilidade Fiscal (LRF), dando ênfase no controle e transparência das finanças e na responsabilização dos gestores.

O Plano Plurianual (PPA) expressa o planejamento e tem como finalidade principal conduzir os gastos públicos de forma racional. Sua importância reside no fato de dar as diretrizes aos governos quanto à realização de despesas de capital, além dos programas de natureza continuada: coleta de lixo, segurança, saúde, educação, dentre outros (Santos et al, 2013).

A Lei de Diretrizes Orçamentária (LDO), introduzida no Direito Financeiro pela Constituição de 1988, faz o elo entre o Plano Plurianual (PPA) e a Lei de Orçamento Anual (LOA). Em outras palavras, a Lei de Diretrizes Orçamentárias (LDO) prioriza as principais metas estabelecidas no Plano Plurianual (PPA) para serem executadas no orçamento anual. A Lei de Diretrizes Orçamentária (LDO) deverá, além de definir as prioridades e nortear a elaboração da Lei de Orçamento Anual (LOA), também dispõe sobre políticas de pessoal e as alterações na legislação tributária. Dessa forma, quando a Administração pretende alterar a norma tributária do exercício seguinte, deverá indicar as intenções na Lei de Diretrizes Orçamentária (LDO), pois acarretam reflexos no total de recursos financeiros com os quais o poder público poderá contar no ano seguinte (Andrade 2006).

A Lei de Diretrizes Orçamentária (LOA) revestida por atos formais prevê as receitas e fixa as despesas que serão realizadas no período de um ano, sendo facultado aos agentes públicos realizar as despesas que na Lei de Diretrizes Orçamentária (LOA) estão fixadas, sem temer sanções administrativas ou

judiciais. Por isso é chamada de lei autorizativa e não impositiva (Andrade, 2006).

Como ressalta Andrade (2002) a Lei de Diretrizes Orçamentárias (LOA) é a materialização do planejamento que expressa seus programas de atuação, discriminando a origem e o montante dos recursos, bem como a natureza e o montante das despesas a serem efetuadas.

Também influenciou na escolha do ano, o fato de que os mecanismos de 
controle mais efetivos das contas municipais ocorreram a partir de 2005, através do Tribunal de Contas do Estado do Paraná (TCE-PR), mesmo que o principal instrumento para esse fim, o SIM- $\mathrm{AM}^{6}$ tenha sido implantado no exercício financeiro de 2002.

\section{Metodologia}

As variáveis usadas nesta pesquisa, no período compreendido entre os anos de 1997 a 2011, tiveram como fonte de informações a Secretaria do Tesouro Nacional (RECEITA FEDERAL 2012), atualizado pelo Índice de Preço ao Consumidor Amplo (IPC-A) a valores de 2011 (IBGE 2012).

Para atender o objetivo desse estudo será usado o modelo econométrico denominado Ajustes de Poligonais a fim de comparar a arrecadação das receitas per capita oriundas do Imposto Sobre Transmissão de Bens Imóveis (ITBI) da mesorregião Metropolitana de Curitiba com as demais mesorregiões do estado. Por fim, foi calculado o Índice de Gini para medir a concentração da arrecadação do Imposto Sobre Transmissão de Bens Imóveis (ITBI) no Estado do Paraná, no período compreendido entre 1997 a 2011. Para melhor compreensão da metodologia foi dividido em dois subtópicos:

\subsection{Variáveis e modelo econométrico}

Para aferir os resultados foi adotado o modelo econométrico de Ajustes de Poligonais usado por Nascimento (2008). O Ajuste das Poligonais originou-se do modelo de diferenças e diferenças (dif-dif) apresentado, por exemplo, em Wooldridge (2001). Esse modelo, conforme ressalta Angrist e Krueger (1998), é limitado, pois não permite captar tendências de comportamento entre dois períodos avaliados e podem, dessa forma, afetar a análise dos resultados.

A utilização do modelo de regressão linear múltipla de Ajustes das Poligonais se fez necessária para detectar mudanças e tendências de alterações das variáveis entre os dois períodos 1997-2004 e 2005-2011 e entre os dois grupos analisados, mesorregião Metropolitana de Curitiba como grupo de controle e demais mesorregiões, grupo de tratamento.

6 Sistema de Informações Municipais implantado inicialmente, em 2002, com ideia inicial de coletar dados que nos anos seguintes de forma gradativa recebeu funções preventivas e regulatórias, tornando assim, mais eficiente no controle das receitas e despesas municipais. 
O modelo de regressão linear múltipla (Nascimento, 2008):

$$
Y_{i}=\alpha_{0}+\beta_{0} T+\varphi_{0} P_{i}(T-\Theta)+\alpha_{1} L_{i}+\beta_{1}(T \times L)+\varphi_{1} P_{i}(T-\Theta) L_{i}+\mu_{i}
$$

Em que:

$Y_{i}$ é a participação percentual da mesorregião Metropolitana de Curitiba no conjunto das demais mesorregiões do Estado do Paraná;

- $\quad P_{i}$ representa a binária que é igual a zero no primeiro período e igual a um no segundo;

- $\quad T$ representa uma variável de tendência;

- $\quad \Theta$ representa a abscissa do vértice, que neste modelo é o ano que delimita o período anterior (1997-2004) e o posterior (2005-2011). Então, $\Theta$ é igual a 2004;

- $\quad \mathrm{L}_{\mathrm{i}}$ representa a binária definida como zero para o grupo de controle e um para o grupo de tratamento. Nessa pesquisa, o grupo de controle é identificado como mesorregião Metropolitana de Curitiba e o grupo de tratamento as demais mesorregiões;

- $\quad \alpha_{0}, \alpha_{1}, \beta_{0}, \beta_{1}, \varphi_{0}$ e $\varphi_{1}$ são os coeficientes;

- $\mu_{i}$ representa o erro aleatório;

- $\quad i$ indica um determinado ano.

Para esse estudo será válido apenas o coeficiente $\varphi_{1}$ da variável $P_{i}(T-\Theta) L_{i}$ que estima a taxa média de aceleração do crescimento per capita do Imposto Sobre Transmissão de Bens Imóveis (ITBI) do grupo de tratamento, no segundo período, em relação ao grupo de controle. Entretanto, para aferir os resultados é necessário montar o modelo econométrico com todas as variáveis da equação 1.

Observa-se o diagnóstico do coeficiente do modelo sempre que for mencionada taxa média, trata-se de uma taxa aritmética de variação e não da taxa geométrica. Essa taxa mostra a variação da arrecadação per capita do Imposto Sobre Transmissão de Bens Imóveis (ITBI).

7 O modelo econométrico de Ajuste das Poligonais foi usado por Nascimento (2008) em defesa da tese para obtenção de título de doutorado na Universidade de São Paulo, intitulada de "Guerra fiscal: uma avaliação com base no PIB, nas receitas de ICMS e na geração de empregos, comparando os estados participantes e não participantes". 


\section{2 Índice de Gini}

Através do Índice de Gini, calcula-se a desigualdade de uma distribuição qualquer. Este coeficiente varia entre o a 1. Quanto mais perto de zero, representa uma distribuição mais significativa, ou seja, no caso deste estudo, um valor de zero significaria uma distribuição uniforme da arrecadação do Imposto Sobre Transmissão de Bens Imóveis (ITBI) em todo Estado do Paraná. Já um coeficiente no valor de 1 apontaria uma concentração da distribuição do Imposto para apenas uma mesorregião do Estado.

Conforme Hoffman (2006), o Índice de Gini pode ser obtido pela seguinte fórmula:

$$
G=1-\left\{\left[\sum_{i=1}^{n}\left(\Phi_{i-1}+\Phi_{i}\right)\right] \div n\right\}
$$

Onde:

- $G$ é o Coeficiente de Gini;

- $\quad i$ são os extratos;

- $\Phi_{i}$ é o valor da proporção acumulada das receitas até o extrato $i$;

- $\quad n$ representa o número de extratos da população e da receita;

O cálculo do Índice de Gini objetiva avaliar o comportamento da arrecadação do Imposto Sobre Transmissão de Bens Imóveis (ITBI), no período de 19972011, no Estado do Paraná, no que tange à sua concentração.

\section{Descrição dos resultados}

Os resultados obtidos com as regressões do modelo de ajuste poligonal estão descritos na Tabela 1, que exibe os coeficientes dos resultados das regressões da mesorregião Metropolitana de Curitiba com as demais mesorregiões do Paraná. As inferências estatísticas foram realizadas com 30 observações, 5 graus de liberdades no numerador e 24 graus de liberdade no denominador, com significância estatística de até $1 \%$. Os estimadores estão dentro do intervalo de confiança e não passam por zero. Todos os coeficientes de determinação são estatisticamente significativos e apresentam resultados, indicando que as variáveis independentes explicam pelo menos $97 \%$ de $Y_{i}$. Quanto ao comportamento da concentração das receitas oriundas do Imposto 
Sobre Transmissão de Bens Imóveis (ITBI), obtida através do Índice de Gini, está exibido na Figura 2.

\subsection{Resultados econométricos}

A Tabela 1 expõem os coeficientes que comparam a mesorregião Metropolitana de Curitiba com as demais mesorregiões do estado. Dessa forma será realizada uma análise descritiva desses resultados.

TABELA 1 - RESULTADOS DAS REGRESSÕES DA MESORREGIÃO METROPOLITANA DE CURITIBA X DEMAIS

\begin{tabular}{|c|c|c|c|c|c|}
\hline \multicolumn{6}{|c|}{$\begin{array}{l}\text { Receitas per capita do ITBI da Mesorregião Metropolitana de Curitiba X } \\
\text { Demais }\end{array}$} \\
\hline Mesorregião & $\varphi_{1}$ & Valor -p & Mesorregião & $\varphi_{1}$ & Valor-p \\
\hline Noroeste & $-7,33$ & 0,00 & Oeste & $-5,00$ & 0,00 \\
\hline $\begin{array}{l}\text { Centro } \\
\text { Ocidental }\end{array}$ & $-9,63$ & 0,00 & Sudoeste & $-5,02$ & 0,00 \\
\hline $\begin{array}{l}\text { Norte } \\
\text { Central }\end{array}$ & $-5,37$ & 0,00 & Centro Sul & $-7,17$ & 0,00 \\
\hline $\begin{array}{l}\text { Norte } \\
\text { Pioneiro }\end{array}$ & $-8,66$ & 0,00 & Sudeste & $-6,22$ & 0,00 \\
\hline $\begin{array}{l}\text { Centro } \\
\text { Oriental }\end{array}$ & $-4,15$ & 0,00 & & & \\
\hline
\end{tabular}

Fonte: Elaborado pelo próprio autor.

Os resultados do modelo econométrico mostram que a aceleração na taxa anual de crescimento das receitas per capita, oriundas do Imposto Sobre Transmissão de Bens Imóveis (ITBI) nas nove mesorregiões do Estado do Paraná é altamente inferior à aceleração da taxa de crescimento da mesorregião Metropolitana de Curitiba, no segundo período. Como na Mesorregião Centro Ocidental o coeficiente mostra que a aceleração média anual na taxa de crescimento da participação percentual nas receitas per capita do Imposto Sobre Transmissão de Bens Imóveis (ITBI) foi inferior à da mesorregião Metropolitana de Curitiba em 9,63\%. Com as demais mesorregiões a aceleração do crescimento no segundo período foi inferior à mesorregião Metropolitana de Curitiba da seguinte forma: mesorregião Noroeste: 7,33\%; mesorregião Norte Central: 5,37\%; mesorregião Norte Pioneiro: 8,66\%; mesorregião Centro Oriental: 4,15\%; mesorregião Oeste: 5,00\%; mesorregião Sudoeste: 5,02\%; mesorregião Centro Sul: 7,17\% e mesorregião Sudeste: 6,22\%. 


\subsection{Resultados do Índice de Gini}

A Figura 1 mostra a curva do Índice de Gini da arrecadação do Imposto Sobre Transmissão de Bens Imóveis (ITBI) no Paraná, no período de 1997 a 2011. Quando se analisa o grau de concentração do Índice verifica-se que no período de 1997 a 2011, se manteve praticamente o mesmo.

FIGURA 1 - ÍNDICE DE GINI DA ARRECADAÇÃO DO ITBI NO PARANÁ ENTRE OS ANOS DE 1997-2011.

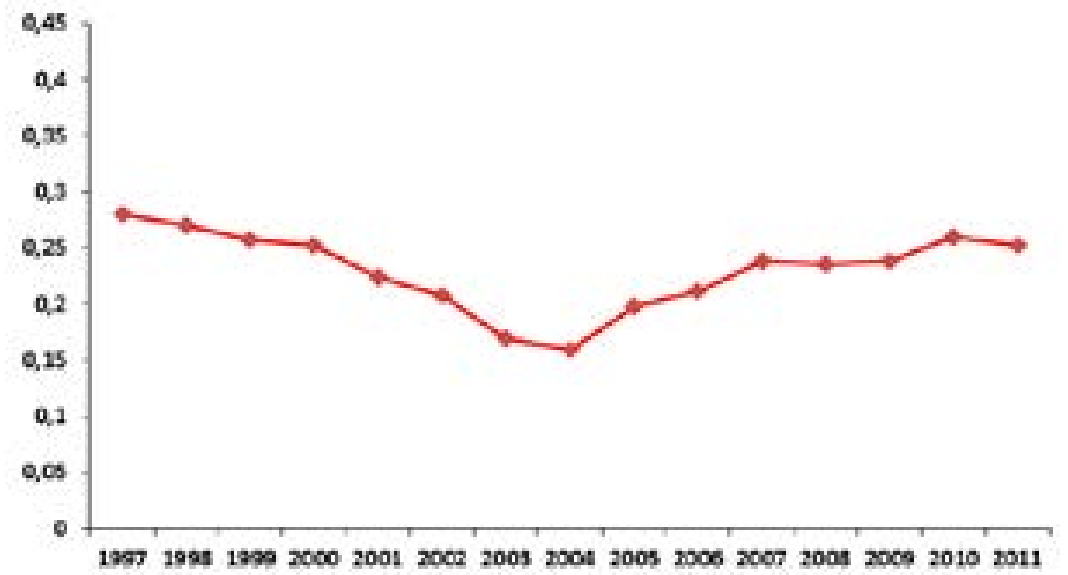

Fonte: Dados da Receita Federal (2012), elaborado pelos Autores.

Entretanto, houve um significativo processo de descentralização no primeiro período, ou seja, entre os anos de 1997-2004, o Índice passou de 0,2841, em 1997 para 0,1660 em 2004, variando negativamente 41,69\%.

No segundo período voltou a crescer, passando de 0,1972 para 0,2551 respectivamente entre os anos de 2005 e 2011, com variação positiva, atingindo $29,36 \%$. Com esses resultados é possível dizer que houve, no período total, uma breve desconcentração da arrecadação do Imposto Sobre Transmissão de Bens Imóveis (ITBI) no Estado do Paraná, com variação negativa de apenas $10,21 \%$ em 15 anos. 


\subsection{Análise dos resultados}

Para subsidiar o entendimento do comportamento das receitas do ITBI no Estado do Paraná, no período de 1997-2011, a Figura 2 ilustra o comportamento dessas receitas durante o período estudado neste artigo na mesorregião Metropolitana de Curitiba comparada às demais receitas dos impostos típicos de municípios (Imposto Sobre Serviços de Qualquer Natureza-ISSQN e Impostos Sobre Propriedade Territorial e Urbana-IPTU). Em 1997 as receitas do Imposto Sobre Transmissão de Bens Imóveis (ITBI) correspondiam a 23,72\% do total das receitas próprias municipais da mesorregião Metropolitana de Curitiba, chegando em 1998 a 26,17\%. A partir de 1999 houve uma acentuada queda, chegando, em 2003, a 15,22\% das receitas próprias municipais. Em 2004 manteve praticamente constante chegando a 15,87\%. Entretanto, a partir de 2005 houve um significativo aumento nas receitas que voltaram a crescer praticamente aos patamares de anteriores, chegando a $24,04 \% \mathrm{em}$ 2010 e a 22,45\% em 2011 das receitas próprias de municípios da mesorregião Metropolitana de Curitiba.

FIGURA 2 - PARTICIPAÇÃO DAS RECEITAS ORIUNDAS DO ITBI NOS IMPOSTOS TÍPICOS DE MUNICÍPIOS DA MESORREGIÃO METROPOLITANA DE CURITIBA, NO PERÍODO 1997-2011.

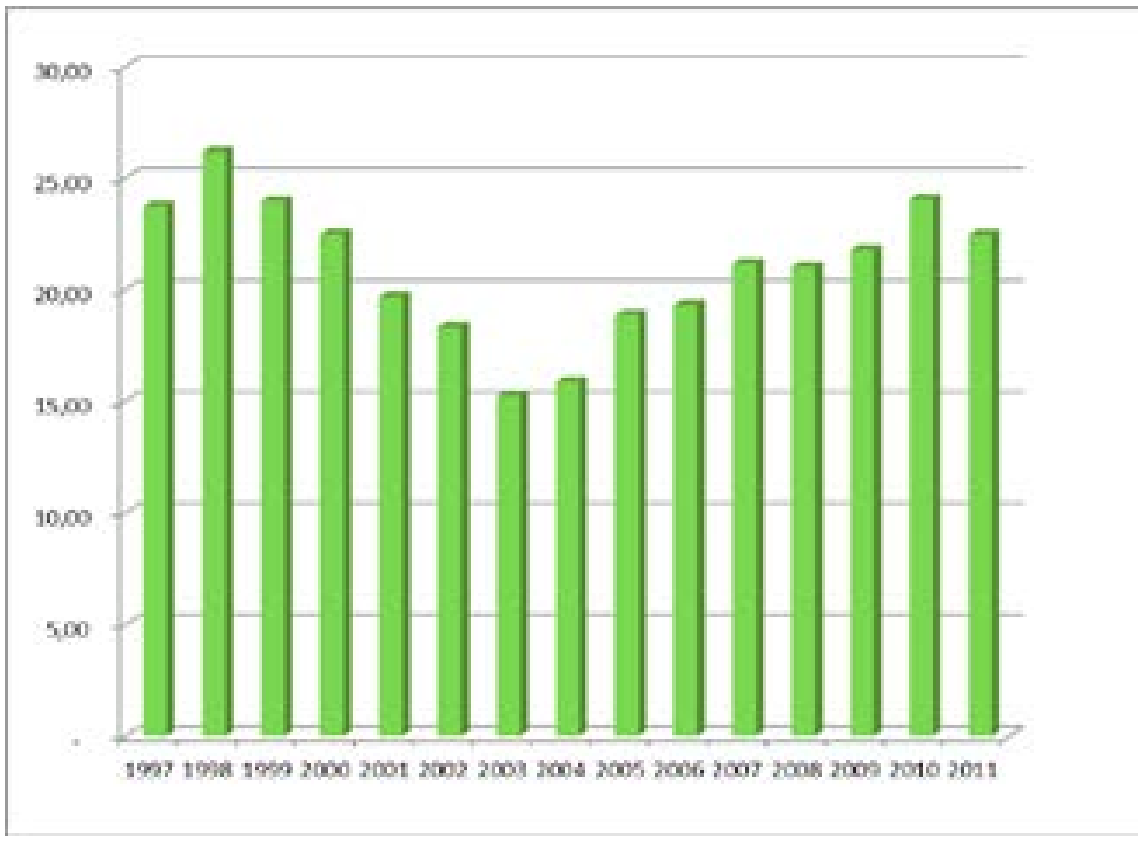

Fonte: Dados da Receita Federal (2012), elaborado pelos Autores. 
Ressalta-se que a hipótese de que o fraco desempenho das demais mesorregiões do estado em relação à mesorregião Metropolitana de Curitiba seria ocasionado pela presença de um processo de migração populacional à Curitiba e municípios vizinhos. Isso realmente aconteceu: a mesorregião Metropolitana de Curitiba, no período de 1997-2004, alcançou uma média na população do estado de 32,33\% e no período de 2005-2011 a participação média foi de $33,46 \%$. Ou seja, houve crescimento médio na participação populacional no segundo período em relação ao primeiro de $3,50 \%$, isso pode ter contribuído para aumentar as transações imobiliárias e consequentemente na arrecadação do Imposto Sobre Transmissão de Bens Imóveis (ITBI).

No sentido inverso a mesorregião Centro Ocidental, que alcançou o pior desempenho na arrecadação per capita do Imposto Sobre Transmissão de Bens Imóveis (ITBI), quando comparada à mesorregião Metropolitana de Curitiba, obteve uma variação negativa de $9,40 \%$ na sua participação populacional no Estado do Paraná, passando de 3,51\%, média do primeiro período para 3,18\%, média do segundo período.

Outro fato que pode ter contribuído para a maior representatividade do Imposto Sobre Transmissão de Bens Imóveis (ITBI) na mesorregião Metropolitana de Curitiba, no segundo período, é a expansão do setor da construção civil nos municípios do litoral paranaense, com ênfase para as cidades de Guaratuba, Matinhos e Pontal do Paraná, com imóveis destinados a aluguéis de veraneio.

Em 2009 a Caixa Econômica Federal, através da Lei 11.977, implementou o "Programa Minha Casa Minha Vida", que permitiu parcerias com os estados, municípios, empresas e movimentos sociais visando a construção 2 milhões de novas casas e apartamentos para a população. Entretanto, esse programa visava atender apenas os municípios acima de 50 mil habitantes (Caixa Econômica Federal 2013).

A mesorregião Metropolitana de Curitiba, além de possuir várias cidades de expansão na construção civil destinada a investimentos no turismo, possui também $24,32 \%$ de suas cidades com população acima de 50 mil habitantes, as quais receberam vultosos investimentos do "Programa Minha Casa Minha Vida”.

Comparando a participação das cidades acima de 50 mil habitantes nas mesorregiões do Paraná, obtêm-se os seguintes resultados - mesorregião Noroeste: 4,92\%; mesorregião Centro Ocidental: 4,00\%; mesorregião Norte Central: 8,86\%; mesorregião Norte Pioneiro: $0 \%$; mesorregião Centro Oriental: 14,29\%; mesorregião Oeste: 6,00\%; mesorregião Sudoeste: 2,70\%; mesorregião Centro Sul: 3,45\%; mesorregião Sudeste: 4,76. Essa diferença da mesorregião Metropolitana de Curitiba com participação de municípios acima de 50 mil habitantes pode explicar o salto da arrecadação do Imposto Sobre Transmissão de Bens Imóveis (ITBI) na participação das receitas típicas de municípios, bem como no Índice de Gini, entre os anos de 2009 e 2010, em 
virtude do "Programa Minha Casa Minha Vida".

Nesse contexto não se pode desconsiderar a eficiência da mesorregião Metropolitana de Curitiba de aumentar suas receitas para atingir as exigências da LRF, a partir de 2005. Fica evidente, que as mesorregiões compostas por municípios menores, têm apresentado dificuldades em ajustar suas contas públicas quando comparadas às mesorregiões com municípios maiores. Outro fator que pode influenciar na arrecadação do Imposto Sobre Transmissão de Bens Imóveis (ITBI) é que os governantes dos menores municípios tem uma proximidade maior do contribuinte que, dessa forma, dificulta aumentar as alíquotas incidentes sobre o fato gerador.

\section{Considerações Finais}

O resultado do Índice de Gini demonstrou uma visível quebra estrutural no processo de concentração das receitas, oriundas do Imposto Sobre Transmissão de Bens Imóveis (ITBI) das dez mesorregiões do Paraná. Até 2004, ano limite do primeiro período deste estudo, houve uma queda acentuada da concentração. Entretanto, a partir de 2005, ano da quebra estrutural tornou a concentrar-se na mesma intensidade que desconcentrou e, por conseguinte, voltou aos mesmos patamares anteriores, com uma variação negativa de $10,21 \%$ em 15 anos.

Isso indica que as mesorregiões compostas de municípios pequenos e de médio porte no que tange ao contingente populacional, não alcançaram comportamentos semelhantes após a quebra de estrutura em 2005, comparadas às mesorregiões compostas por municípios maiores. Ou seja, as mesorregiões que são compostas por municípios de maior número populacional, desenvolveram arrecadações de Imposto Sobre Transmissão de Bens Imóveis (ITBI), no segundo período, compreendido entre os anos de 2005 a 2011, com mais eficiência.

Os resultados econométricos convergem com o Índice de Gini, quando mostram que todas as mesorregiões do estado obtiveram, no segundo período, taxas negativas de crescimento na participação média nas receitas oriundas do Imposto Sobre Transmissão de Bens Imóveis (ITBI) comparadas à mesorregião Metropolitana de Curitiba. As Mesorregiões que apresentaram as piores taxas de participações negativas na arrecadação do Imposto Sobre Transmissão de Bens Imóveis (ITBI) foram nessa ordem: mesorregião Centro Ocidental; mesorregião Norte Pioneiro, mesorregião Noroeste e Centro Sul. A mesorregião Centro Ocidental, apesar de ser compostas de 25 municípios, em 2011, apenas Campo Mourão alcançou 80 mil habitantes e a maioria das demais cidades tem em torno de 10 mil habitantes. A mesorregião Norte 
Pioneiro, apesar de ser formada por quarenta e seis municípios, apenas dois conseguiu alcançar 40 mil habitantes em 2011. A mesorregião Noroeste que contêm sessenta municípios, apenas Umuarama ultrapassou 100 mil habitantes, Cianorte e Paranavaí, respectivamente alcançaram 70 e 80 mil habitantes (IBGE, 2012).

As melhores taxas foram alcançadas quando se compara a mesorregião Metropolitana de Curitiba com a mesorregião Oeste, mesorregião Centro Oriental, mesorregião Sudoeste e mesorregião Norte Central. A mesorregião Oeste é composta de municípios como Toledo com mais de 120 mil habitantes e Foz do Iguaçu e Cascavel, respectivamente com mais de 250 e 280 mil habitantes. A mesorregião Centro Oriental, apesar de ser composta de apenas quatorze municípios, é composta de cidades que alcançaram um grande contingente populacional, com destaque para Ponta Grossa que ultrapassou 314 mil habitantes em 2011. Ainda possui dois municípios com mais de 60 mil habitantes, além da maioria dos outros municípios terem em torno de 20 a 30 mil habitantes (IBGE, 2012).

A mesorregião Sudoeste tem como destaque os municípios de Pato Branco e Francisco Beltrão, que têm em torno de 80 mil habitantes. E a mesorregião Norte Central, que é composta de duas cidades com alta população como Londrina com mais de 500 mil habitantes e Maringá que ultrapassou 360 mil. Ainda contemplam vários municípios que possuem em torno de $100 \mathrm{mil}$ habitantes, como Sarandi, Apucarana e Arapongas. Ressalta-se que a mesorregião Norte Central e Mesorregião Oeste, juntamente com a mesorregião Metropolitana de Curitiba apresentam os melhores desempenhos econômicos do Paraná (IPARDES, 2012).

Dessa forma, os resultados do Índice de Gini e econométricos indicam, que após a quebra estrutural ocorrida em 2005, em razão dos ajustes nas contas públicas exigidas pela a Lei de Responsabilidade Fiscal (LRF), às mesorregiões que contemplam os menores municípios em termos populacionais obtiveram resultados menos expressivos que as mesorregiões com maior número de habitantes.

Ressalta-se que as avaliações sobre o tema não foram esgotadas neste artigo e muitos estudos devem ser realizados para o real entendimento sobre a tributação do Imposto Sobre Transmissão de Bens Imóveis (ITBI). Outros estudos que comparem a dinâmica do Imposto Sobre Transmissão de Bens Imóveis (ITBI) com os demais impostos de competência municipal como o Imposto Predial Territorial e Urbano e Imposto Sobre Serviços de Qualquer Natureza (ISSQN) podem ajudar a entender a dinâmica comportamental das receitas originadas do Imposto Sobre Transmissão de Bens Imóveis (ITBI). Portanto, com este estudo espera-se ter contribuído para um melhor entendimento da temática abordada, visto que são escassos os trabalhos sobre as receitas do Imposto Sobre Transmissão de Bens Imóveis (ITBI) na área das Ciências Econômicas. 


\section{Referências}

Andrade, N. A. (2002). Contabilidade Pública na Gestão Municipal. São Paulo: Atlas.

Andrade, N. A. (2006). Planejamento Governamental Para Municípios. São Paulo: Atlas.

Angrist, J.d \& Krueger, A.b. (1998). Empirical strategies in labor economics. In Working Paper, $v$. 401 Princeton: Princeton University.

Barreto, A. F. (2009). Curso de Direito Tributário Municipal. São Paulo: Saraiva.

Brasil. Constituição (1988). “Constituição da República Federativa do Brasil”. URL [On line]: http://presrepublica.jusbrasil.com.br/legislacao/91972/constituicao-da-republica-federativa-do-brasil-1988\#art-156--inc-II. Acesso em: 21 de novembro de 2013.

Caixa Econômica Federal (2013). "Minha casa, Minha vida”. URL [On line]: http:// www.caixa.gov.br. Acesso em 13 de agosto de 2013.

Código Tributário Nacional. Constituição Federal. Legislação Tributária. Obra coletiva de autoria da Editora Revista dos Tribunais (2011). São Paulo: Revista dos Tribunais.

Conti, J. M. (1999). “O Imposto sobre a Transmissão de Bens Imóveis (ITBI): principais questões.” Jus Navigandi. 4 (36). URL [On line]: http://jus.com.br/ revista/texto/1401. Acesso em 27 novembro 2012.

Dias, M.a. (2009). “James Buchanan e a "Política” na Escolha Pública.” Ponto-e-vírgula, 6: 201-217. [On line]: http://www.pucsp.br/ponto-e-virgula/n6/ artigos/pdf/pv6-16-marcoantonio.pdf. Acesso em 14 de março de 2013.

Esping-Andersen, G.(1991) "As Três Economias Políticas do Welfare State”. Lua Nova, 24. [On line]: http://www.scielo.br/scielo.php?pid=So10264451991000200006\&script=sci_arttext. Acesso em 14 de março de 2013.

Giambiagi, F. \& Além, A.c. (2000). Finanças Públicas - Teoria e Prática no Brasil. Rio de Janeiro: Campus.

Hoffman, R. (2006). Estatística para Economistas. São Paulo: Saraiva.

IBGE - Instituto Brasileiro de Geografia e Estatística (2012). "Brasil”. URL [On line]: http://www.ibge.gov.br. Acesso em 25 de outubro de 2012.

IPARDES - Instituto Paranaense de Desenvolvimento Econômico. (2013). "Paraná". URL [On line] http://www.ipardes.gov.br . Acesso em 13 de março de 2013.

Lino, P. (2001). Comentários à Lei de Responsabilidade Fiscal. São Paulo: Atlas.

Nascimento, S. P. (2008). Guerra fiscal: uma avaliação com base no PIB, nas receitas de ICMS e na geração de empregos, comparando os estados participantes e não participantes. São Paulo: tese de doutorado, Universidade Estadual de São Paulo.

Oliveira, J.j. De M. (2009). Impostos Municipais: ISS, IPTU, ITBI. São Paulo. Saraiva.

Receita Federal (2012). "Secretaria do Tesouro Nacional”. URL [On line]: http:// 
SANTOS, R. G. dos; NASCIMENTO, S. P. do. Os impactos da Lei de Responsabilidade Fiscal sobre as Receitas....

www.receita.fazenda.gov.br. Acesso em 23 de outubro de 2012.

Riani, F. (1997). Economia do Setor Público: Uma Abordagem Introdutória. São Paulo: Atlas.

SESA - Secretaria da Saúde (2013). "Paraná”. URL [On line] www.saude.pr.gov.br. Acesso em 13 de março de 2013.

Santos, R. G.; Nascimento, S. P.; Felema, J. Análise das Receitas Oriundas do ISSQN no Paraná: Os Impactos da Lei de Responsabilidade Fiscal. Revista Economia e Região, vol. 1. n. 2, 2013. Acesso em o6 de janeiro de 2014.

Santos, R. G.; Nascimento, S.p. A arrecadação do IPTU, no Estado do Paraná, no período de 1997 a 2011: um olhar sob os impactos da Lei de responsabilidade Fiscal. Revista Economia e Desenvolvimento, vol. 26, n. 1, 2014. Acesso em 23 de setembro de 2014 .

Wooldridge, J. (2001). Econometric analysis of cross and panel data. Cambridge: The MIT. 